\title{
Causes, timing, and modes of death in a tertiary pediatric intensive care unit
}

\section{Five years' experience}

Ayman Al-Eyadhy, MD, Mohamad-Hani Temsah, MD, FRCPCH, Gamal M. Hasan, MD, Mohammed Almazyad, MD, Ali A. Alhaboob, MD, Majed Alabdulhafid, MD, Fahad Alsohime, MD, Ahmed S. Alzahrani, MBBS, Abdullah M. Alammari, MBBS, Faisal S. Abunohaiah, MBBS, Nawaf F. Alfawzan, MBBS, Suhail S. Alghamdi, MBBS.

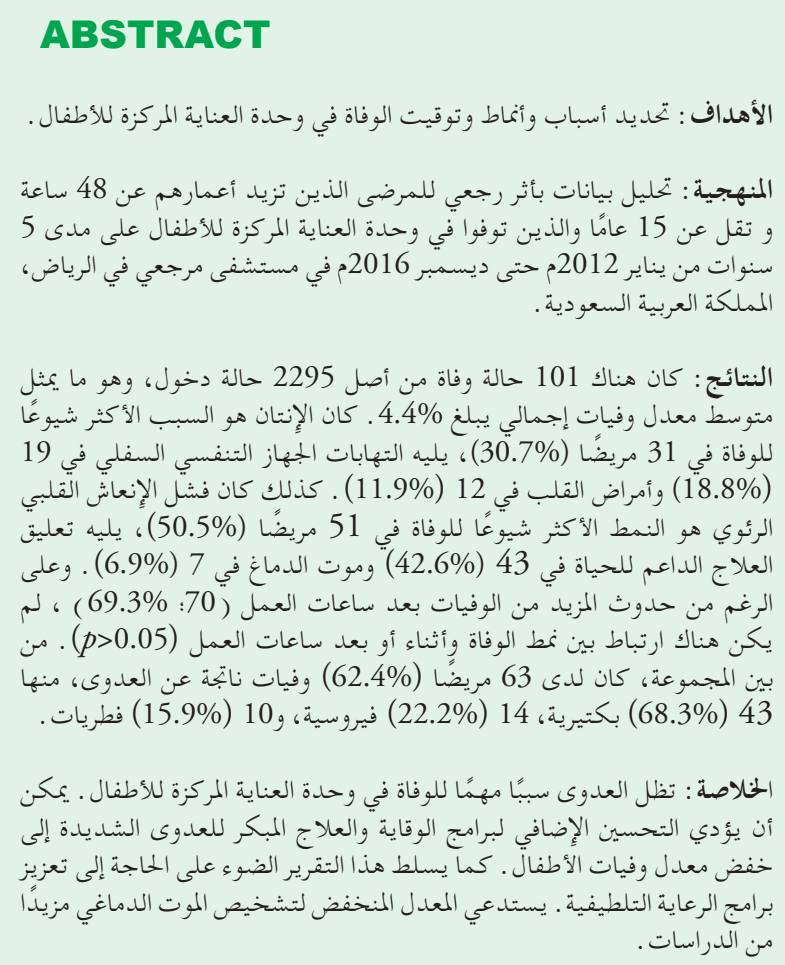

Objectives: To identify the causes, modes, and timing of death in a tertiary pediatric intensive care unit (PICU).

Methods: This is a retrospective data analysis of patients older than 48 hours and younger than 15 years who died in the PICU over a 5-year period from January 2012 until December 2016 at a tertiary hospital in Riyadh, Saudi Arabia.

Results: There were 101 deaths out of 2295 admissions, representing average crude mortality rate of $4.4 \%$. Sepsis was the most common cause of death in 31 patients $(30.7 \%)$, followed by lower respiratory tract infections in $19(18.8 \%)$, and cardiac diseases in 12 (11.9\%). Failed cardiopulmonary resuscitation was the most common mode of death in 51 patients $(50.5 \%)$, followed by withholding life-sustaining

treatment in 43 (42.6\%), and brain death in 7 (6.9\%). Although more deaths occurred during after hours $(\mathrm{n}=70 ; 69.3 \%)$, there was no significant correlation between mode of death and working hours vs. after hours $(p>0.05)$. Among the cohort, 63 patients $(62.4 \%)$ had an infection-attributed mortality, of which $43(68.3 \%)$ were bacterial, $14(22.2 \%)$ were viral, and 10 (15.9\%) were fungal.

Conclusion: Infections remain a significant cause of death in the PICU. Further improvement of prevention programs and early therapy of severe infections could lower pediatric mortality. This report highlights the need for enhancing palliative care programs. The low rate of brain death diagnoses warrants further investigation.

Keywords: causes of death, infections, mode of death, pediatrics, Saudi

$$
\begin{aligned}
& \text { Saudi Med J 2021; Vol. } 42 \text { (11): 1186-1194 } \\
& \text { doi: } 10.15537 / \text { smj.2021.42.11.20210508 }
\end{aligned}
$$

From the College of Medicine (Al-Eyadhy, Temsah, Almazyad, Alhaboob, Alabdulhafid, Alsohime, Alzahrani, Alammari, Abunohaiah, Alfawzan, Alghamdi), King Saud University; from the Department of Pediatric (Al-Eyadhy, Temsah, Almazyad, Alhaboob, Alabdulhafid, Alsohime), Pediatric Intensive Care Unit, College of Medicine, King Saud University, Riyadh, Kingdom of Saudi Arabia, from the Department of Pediatrics (Hasan), Pediatric Intensive Care Unit, Faculty of Medicine, Assiut University, Assiut, Egypt, and from the Department of Pediatrics (Hasan), Pediatric Intensive Care Unit, Sheikh Shakhbout Medical City, Abu Dhabi, United Arab Emirates.

Received 27th June 2021. Accepted 28th September 2021.

Address correspondence and reprint request to: Dr. Ayman A. Al-Eyadhy, Pediatric Intensive Care Unit, Department of Pediatrics, College of Medicine, King Saud University, Riyadh, Kingdom of Saudi Arabia. E-mail: aleyadhy@ksu.edu.sa

ORCID ID: https://orcid.org/0000-0002-6051-9125 
T here are several causes of mortality in the pediatric intensive care unit (PICU), where the majority of pediatric deaths occur. Respiratory failure, sepsis, cancer, cardiac diseases, and neurological injuries are the most common causes of PICU mortality. ${ }^{1}$ Whereas respiratory failure and neoplastic conditions were reported as the most common causes of death in developed countries, sepsis and sepsis-related diagnoses were the most common causes in developing countries. ${ }^{1-3}$ Understanding the epidemiology and characteristics of pediatric mortality is difficult due to changes in healthcare services and their impact on public health.

Patterns and changes in modes of death over time are also important. Modes of death are categorized into 3 main types: withholding life-sustaining treatment (WLST), brain death, and failed cardiopulmonary resuscitation (F-CPR). ${ }^{1}$ Studies indicate that WLST is the most common mode of death in Europe, the United States (US), and Australia among children in PICU..$^{4-7}$ However, the question regarding common causes and modes of deaths in pediatrics remains open in Saudi Arabia due to a scarcity of studies, and additional information is required to further clarify local patterns and changes. ${ }^{8}$ Understanding these changes and patterns could facilitate further planning of effective quality initiatives, optimize resource allocation, and reframe training programs to deal with end-of-life issues. ${ }^{5}$ Therefore, this study aimed to provide further insight into common causes, modes, and timing of death in the PICU by reviewing local data.

Methods. This retrospective cohort study was conducted at King Saud University Medical City, Riyadh, Saudi Arabia. Our PICU is a 14-bed, tertiarylevel, combined medical and surgical (non-cardiac) unit staffed by certified pediatric intensivists. Although our PICU receive referred cases from other institutions, most of the admissions to the PICU are from emergency department and hospital wards. An accredited pediatric intensive care fellowship program is run at the PICU. Data was collected for the period starting from January 2012 until December 2016. Data was collected for patients who were older than 48 hours and younger than 15 years old and had been admitted to the PICU with a recorded outcome of death. Deaths outside the PICU or the specified age ranges were excluded. The mortalities less than 48 hours were not included to avoid mortalities due to perinatal causes.

Disclosure. Authors have no conflict of interests, and the work was not supported or funded by any drug company.
Data retrieved through medical records included demographic data (age and gender) and admission data (date, time of PICU admission and whether this day was a weekday or weekend). Collected clinical data included primary cause of death, mode of death (WLST, brain death, or F-CPR), date and time of death (year, month, day, hour), and the patient's code status upon death (whether active code or do not resuscitate [DNR]).

Modes of death were classified as follows: F-CPR, defined as failure of resuscitation procedures and medications leading to death; WLST, defined as a conscious decision to stop or not to initiate a treatment if such treatment is judged by the treating team to be futile (commonly referred to as a DNR order); and brain death, defined as permanent cessation of entire brain functions following the Saudi Center for Organ Transplant definition and diagnostic criteria. ${ }^{9,10}$ The primary cause of death was defined as the most important diagnosis that led to death, and each cause of death was assigned to a categorical diagnosis based on the system or mechanism of injury associated with it. For instance, the cardiac disease refers to congenital and acquired cardiac conditions leading to heart failure. For sepsis, the definition of the international consensus conference on pediatric sepsis was considered. ${ }^{11}$

Times of death were divided into working hours, which included weekdays from 7:00 to 15:59, and after hours, which included weekdays from 16:00 to 6:59 and all hours during the weekend. The demographics and outcome data, such as causes and modes of death, are presented as frequencies or percentages. The dichotomous/categorical variables are expressed as proportions, while the continuous variables are expressed as a median and standard deviation or median and interquartile range.

To compare the groups, statistical analyses were conducted using Chi-squared $\left(\chi^{2}\right)$ tests for categorical variables. For continuous variables, t-tests and MannWhitney $U$ tests were used to compare means and medians. The bivariate analysis was carried out to test correlations between modes of death and other variables in relation to working hours and after hours. Additionally, we compared modes of death and other variables in relation to PICU length of stay to test for different mortality profiles for those who died within the first week of admission to the PICU compared to those who died later. ${ }^{1}$ The Statistical Package for the Social Sciences, Version 23 (IBM Corp., Armonk, NY, USA) was used for the statistical analysis.

This study was conducted after approval by the Institutional Review Board of King Saud University, approval project number (E-17-2310). All data were 
de-identified during data analysis. Due its retrospective design and anonymous data, informed consent was waived by the Institutional Review Board.

Results. There were 101 deaths out of 2295 admissions from 2012-2016, accounting for average crude mortality rate of $4.4 \%$. Of these 101 deaths, 52 $(51.5 \%)$ were females and $49(48.5 \%)$ were males. The mean age was $49.9 \pm 53.4$ months. Almost half of the patients $(n=49,48.5 \%)$ who died were 24 months or younger. Most deaths $(n=70,69.3 \%)$ occurred during the after hours. Table 1 shows the distribution of patients based on demographics and clinical characteristics.

The code status upon death was DNR order in $50(49.5 \%)$ patients, and their mode of death was either brain death or WLST. Sepsis was the most commonly reported cause of death $(30.7 \%)$, followed by lower respiratory infection $(18.8 \%)$ and cardiovascular causes (11.9\%). Among the 101 reported deaths, most of the patients $(n=63,62.4 \%)$ presented with an infection

Table 1 - Demographics and clinical characteristics of mortalities $(\mathrm{N}=101)$.

\begin{tabular}{lc}
\hline Variables & $\mathbf{n}(\%)$ \\
\hline Female & $52(51.5)$ \\
Age (months), Mean $\pm S D$ & $49.9 \pm 53.4$ \\
$\leq 12$ months & $36(35.6)$ \\
$12-24$ months & $13(12.9)$ \\
$>24$ months & $52(51.5)$ \\
Hospital admission in the working hours & $86(85.1)$ \\
Categorical diagnosis & \\
Respiratory & $37(36.6)$ \\
Sepsis & $31(30.7)$ \\
Cardiac disease & $12(11.9)$ \\
Tumors & $7(6.9)$ \\
CNS & $6(5.9)$ \\
Trauma & $5(5.0)$ \\
Other & $3(3.0)$ \\
Time of death & \\
Working hours & $31(30.7)$ \\
After hours & $70(69.3)$ \\
Quarter of the year & \\
1st quarter & $28(27.7)$ \\
2nd quarter & $23(22.8)$ \\
3rd quarter & $23(22.8)$ \\
4th quarter & $27(26.7)$ \\
Length of stay & \\
Hospital, median (Qrt.1-Qrt.3) & $10(3,37)$ \\
PICU length of stay days, median (Qrt.1-Qrt.3) & $6(2,18.5)$ \\
\hline SD: standard deviation, CNS: central nervous system, PICU: pediatric \\
& \\
\hline & intensive care unit \\
\hline
\end{tabular}

upon PICU admission. Bacterial infection was the highest reported type of infection $(n=43,68.3 \%)$, all of which had positive blood cultures. Respiratory samples such as tracheal aspirate and broncho-alveolar lavage fluid cultures were reported in $33(28.2 \%)$ patients. Other sample sites included urine, cerebrospinal fluid (CSF), skin, and peritoneal fluid or drain. The modes and causes of death are summarized in Table 2. The causes of brain death were traumatic brain injury in 4 cases, brain anoxic injury following cardiac arrest and return of spontaneous circulation in 2 cases, and one patient suffered from severe hypoxic insult following refractory and prolong seizer due to advanced neurodegenerative disease.

The bivariate analysis of mortalities in relation to the working or after-hours' time of death revealed similar distribution with no significant correlation between

Table 2 - Modes and causes of mortalities ( $\mathrm{N}=101)$.

\begin{tabular}{|c|c|}
\hline Variables & n (\%) \\
\hline \multicolumn{2}{|l|}{ Mode of death } \\
\hline $\mathrm{F}-\mathrm{CPR}$ & $51(50.5)$ \\
\hline WLST & $43(42.6)$ \\
\hline Brain death & $7(6.9)$ \\
\hline DNR order & $50(49.5)$ \\
\hline \multicolumn{2}{|l|}{ Cause of death } \\
\hline Shock - septic & $31(30.7)$ \\
\hline Lower respiratory infection & $19(18.8)$ \\
\hline Cardiac diseases & $12(11.9)$ \\
\hline Respiratory failure due to CNS disease & $12(11.9)$ \\
\hline Tumors & $7(6.9)$ \\
\hline Pulmonary hemorrhage & $6(5.9)$ \\
\hline Other* & $14(13.9)$ \\
\hline Presented with infection upon admission & $63(62.4)$ \\
\hline \multicolumn{2}{|l|}{ Type of infection identified across admission ${ }^{* *}$} \\
\hline Bacterial & $43(68.3)$ \\
\hline Viral & $14(22.2)$ \\
\hline Fungal & $10(15.9)$ \\
\hline Undetermined $^{\#}$ & $4(6.3)$ \\
\hline \multicolumn{2}{|l|}{ Site of sample } \\
\hline Blood & $43(36.7)$ \\
\hline Respiratory & $33(28.2)$ \\
\hline Urine & $20(17.1)$ \\
\hline CSF & $9(7.7)$ \\
\hline Other sites ${ }^{\circledR}$ & $12(10.3)$ \\
\hline \multicolumn{2}{|c|}{$\begin{array}{l}\text { F-CPR: failed cardiopulmonary resuscitation, WLST: withholding life- } \\
\text { sustaining treatment, DNR: do not resuscitate, CNS: central nervous } \\
\text { system, CSF: cerebrospinal fluid, }{ }^{*} \text { others include: renal failure, liver } \\
\text { failure, primary immunodeficiency, trauma, massive stroke, CNS } \\
\text { infections, and intracranial hemorrhage. }{ }^{* *} \text { Eight patients had mixed } \\
\text { infections. }{ }^{*} \text { Clinically suspected infection but no positive cultures. }{ }^{\circledR} \\
\text { Include skin, peritoneal and body fluid }\end{array}$} \\
\hline
\end{tabular}


these modes of death and the time of death. During after hours, F-CPR was reported in $36(51.4 \%)$ patients, followed by WLST in $29(41.4 \%)$ and brain death in $5(7.1 \%)$. Appendix 1 shows a bivariate analysis of mortalities in relation to working and after-hours' time of death.

Almost half (51.5\%) of the patients died in less than one week of their PICU admission. Patients who were presented with infections upon admission were more likely to stay a week or more in the PICU $(p=0.025)$. Also, patients who stayed a week or more in the PICU were found to have significantly higher numbers of bacterial $(p=0.039)$ and fungal $(p=0.015)$ infections. Death following WLST was significantly higher in patients who stayed one week or more in the PICU ( $p=0.013)$. Similarly, mechanical ventilation was higher among patients who stayed one week or more in the PICU ( $p=0.045)$ as well as patients who received total parenteral nutrition $(p=0.021)$. Finally, regarding mortalities in this cohort, patients who had an assigned DNR status by the caring medical team were more likely to have stayed a week or more in the PICU $(p=0.007)$. Table 3 shows a bivariate analysis of PICU length of stay in relation to patient demographics and clinical characteristics.

Discussion. Differences in the PICU mortality rate in different regions in Saudi Arabia have been noted. In this study, the crude mortality rate was $4.4 \%$, which is lower than previously reported local data $(6.5 \%) .{ }^{8}$ Our PICU crude mortality rate was marginally higher than international rates reported from developed countries (2.4-4.1\%) but lower than reported crude mortality rates in developing countries (12.9-18\%). ${ }^{2,12}$ The differences in these unadjusted mortality rates are due to multiple factors, such as the population age range included in these reports and available healthcare resources. For instance, patients up to 14 years old can be admitted to the PICU in Saudi Arabia, whereas older pediatric patients are cared for in adult ICUs. This might explain the marginally higher locally reported mortality rates as more deaths are predicted in young infants and children compared to adolescents. ${ }^{1,13}$ Furthermore, population distribution may have similar implications, as 30.4\% of the Saudi population are younger than 14 years compared to only $19.1 \%$ of US citizens. ${ }^{14,15}$ Another possible reason for the difference in mortality rates is the availability of long-term facilities, home care, and advanced palliative care programs. In developed countries, most chronic or terminal patients are cared for outside of the PICU, and thus their mortality rates are not reflected in the data. The socio-demographic index (SDI) is another factor affecting mortality rate, with lower SDI countries having a higher mortality rate in general. ${ }^{16}$ Nevertheless, crude mortality rates are generally inaccurate for benchmarking, and adjusted mortality rates should be implemented instead as a standardized quality indicator.

Regarding the demographic characteristics of deaths among pediatric patients, no difference in mortality was found regarding the gender. However, a pattern was found for age, with a higher percentage rate reported among younger patients. This finding is comparable to some US-based hospitals mortalities, which reported a median age of 24 months among their pediatric mortalties. ${ }^{1}$ Moreover, the reported pattern of higher mortality in the younger age group in our study is consistent with the global mortality estimate over the last decade. ${ }^{13}$ These findings emphasize the high risk among this age group for health care providers and health authorities. Further clarifying the underlying risk factors that lead to death among this age group can assist authorities with implementing strategies to minimize these risks and save lives.

Infections remain a major concern in childhood mortality. ${ }^{17,18}$ More than half of the patients in this study had an infection associated with their primary cause of death, indicating that septic shock was the most common cause of death. These results show a comparable trend to the causes of death in previous reports, in which sepsis-related diagnoses were the main causes of death in developing, and to a lesser extent, developed countries' PICUs. ${ }^{12,19}$

The age profile of patients who died from septic shock in this cohort revealed that sepsis diagnosis was more frequent in a younger age group (median age of 7 months), which was generally younger than the ages of children who died from other causes. In contrast to older children, infants, including those born prematurely, have a higher rate of severe sepsis and thus a higher risk of dying from sepsis. ${ }^{20}$

The highest number of infections were detected in blood samples followed by samples taken from the respiratory system. This indicates that lower respiratory infections were the second common cause of death in this cohort, which is similar to the global trend. ${ }^{21}$ This highlights an area of ongoing challenge for more research into such preventable and curable causes of death. The early recognition and initiation of broadspectrum antimicrobials and meticulous surveillance for infections is warranted, as many patients may develop co-infections through their complex PICU course. ${ }^{22-24}$

Because F-CPR is the default mode of death, we expected it to be more common compared to the other 
Table 3 - Length of PICU stay in relation to demographic and clinical characteristics, with bivariate analysis for groups with shorter and longer than one-week PICU stay.

\begin{tabular}{|c|c|c|c|c|}
\hline \multirow[t]{2}{*}{ Demographics } & $<1$ week $(\mathrm{n}=52)$ & $\geq 1$ week $(n=49)$ & Test statistic & $P$-value \\
\hline & \multicolumn{2}{|c|}{$\mathrm{n}(\%)$} & & \\
\hline \multicolumn{5}{|l|}{ Gender } \\
\hline $\begin{array}{l}\text { Female } \\
\text { Male }\end{array}$ & $\begin{array}{l}27(51.9) \\
25(48.1)\end{array}$ & $\begin{array}{l}25(51.0) \\
24(49)\end{array}$ & $\chi^{2}(1)=0.01$ & 0.928 \\
\hline Age (months), mean $\pm S D$ & $52.81 \pm 51.6$ & $46.8 \pm 55.6$ & $\mathrm{t}(99)=0.60$ & 0.889 \\
\hline Presented with infections upon admission & $27(51.9)$ & $36(76.5)$ & $\chi^{2}(1)=4.99$ & 0.025 \\
\hline \multicolumn{5}{|l|}{ Type of infection identified across admission } \\
\hline $\begin{array}{l}\text { Bacterial } \\
\text { Viral } \\
\text { Fungal } \\
\text { Undetermined* }\end{array}$ & $\begin{array}{l}17(32.7) \\
7(13.5) \\
1(1.9) \\
3(5.8)\end{array}$ & $\begin{array}{l}26(53.1) \\
7(14.3) \\
9(18.4) \\
1(2.0)\end{array}$ & $\begin{array}{l}\chi^{2}(1)=4.30 \\
\chi^{2}(1)=0.02 \\
\chi^{2}(1)=5.92 \\
\chi^{2}(1)=0.202\end{array}$ & $\begin{array}{l}0.039 \\
0.905 \\
0.015 \\
0.653\end{array}$ \\
\hline \multicolumn{5}{|l|}{ Intensive care interventions } \\
\hline $\begin{array}{l}\text { Mechanical ventilation } \\
\text { Total parenteral nutrition } \\
\text { Inotropic support } \\
\text { Blood product transfusions }\end{array}$ & $\begin{array}{c}44(84.6) \\
4(7.7) \\
39(75.0) \\
21(40.4)\end{array}$ & $\begin{array}{l}48(98.0) \\
12(24.5) \\
36(73.5) \\
21(42.9)\end{array}$ & $\begin{array}{l}\chi^{2}(1)=4.01 \\
\chi^{2}(1)=4.34 \\
\chi^{2}(1)=0.03 \\
\chi^{2}(1)=0.06\end{array}$ & $\begin{array}{l}0.045 \\
0.021 \\
0.860 \\
0.801\end{array}$ \\
\hline \multicolumn{5}{|l|}{ Mode of death } \\
\hline $\begin{array}{l}\text { F-CPR } \\
\text { WLST } \\
\text { Brain death }\end{array}$ & $\begin{array}{c}31(59.6) \\
16(30.8) \\
5(9.6)\end{array}$ & $\begin{aligned} 20 & (40.8) \\
27 & (55.1) \\
2 & (4.1)\end{aligned}$ & $\begin{array}{l}\chi^{2}(1)=3.57 \\
\chi^{2}(1)=6.11 \\
\chi^{2}(1)=0.50\end{array}$ & $\begin{array}{l}0.059 \\
0.013 \\
0.482\end{array}$ \\
\hline DNR order & $19(36.6)$ & $31(63.7)$ & $\chi^{2}(1)=7.30$ & 0.007 \\
\hline \multicolumn{5}{|l|}{ Cause of death } \\
\hline $\begin{array}{l}\text { Shock - septic } \\
\text { Lower respiratory infection } \\
\text { Cardiac diseases } \\
\text { Respiratory failure secondary to CNS disease } \\
\text { Tumors } \\
\text { Pulmonary hemorrhage } \\
\text { Other }\end{array}$ & $\begin{array}{l}13(25.0) \\
9(17.3) \\
10(19.2) \\
5(9.6) \\
3(5.8) \\
4(7.7) \\
8(15.4)\end{array}$ & $\begin{array}{c}18(36.7) \\
10(20.4) \\
2(4.1) \\
7(14.3) \\
4(8.2) \\
2(4.1) \\
6(12.2)\end{array}$ & $\chi^{2}(6)=9.7$ & 0.14 \\
\hline
\end{tabular}

PICU: pediatric intensive care unit, SD: standard deviation, F-CPR: failed cardiopulmonary resuscitation, WLST: withholding life-sustaining treatment, DNR: do not resuscitate, CNS: central nervous system

modes of death. The literature varies regarding the frequency of different death modes, both regionally and globally. ${ }^{1,6,8,12}$ For instance, Chehab et al, ${ }^{25}$ described F-CPR as the most common mode of death in a tertiary ICU in Saudi Arabia. In contrast, Alayed et al, ${ }^{8}$ described WLST as the most common mode of death in another Saudi hospital. The differences between these studies could be related to the types and severity of cases, as hemato-oncology causes were the main cause of death in Alayed et $\mathrm{al}^{8}{ }^{8}$ cohort. Multiple studies have reported WLST as the most common mode of death in Western hospitals. ${ }^{1,5-7,26}$ The reported differences are likely to be multifactorial; cultural differences, income, and education contribute to different perceptions on DNR orders. For instance, the community's religious perspectives regarding the concept of DNR can play an important role. Hileli et al, ${ }^{27}$ reported that $61.5 \%$ of Muslim parents and $88.9 \%$ of Christian parents consented for DNR for their children with solid tumors, and higher income and education significantly increased the decision to sign a DNR. Hafez at al, ${ }^{28}$ demonstrated that Islamic faith positively impacted the care and influenced the acceptance of decisions in relation to end-of-life issues, in a cohort of Saudi mothers caring for children with terminal illnesses. Another crucial factor is the perception of doubts regarding legal protections and liability lawsuits, which may hinder or delay the application of DNR orders. ${ }^{29}$ The integration of well-trained palliative care staff within or in liaison with the PICU could largely facilitate communication between health care providers and families about end of life. Such improvements in communication might prevent futile interventions and result in a smooth transition towards better patient comfort and resources allocation. $1,4,6,7,12$

In this cohort, patients with WLST had a higher median length of both hospital and PICU stay. Sicker patients could need further treatments and interventions, which eventually become futile. Other factors contributing to a longer stay could be a delay 
in the determination of code status for those chronic patients who were pre-identified as candidates for a DNR order. Additionally, communication failure between the health care team and family may contribute to longer stays for patients whose lives ended with WLST. Multiple reports have stated that patients with chronic and complex diseases tend to have limitation of life support treatment. ${ }^{12,25}$ Although disparities in end-of-life goals for chronic and complex patients occur, they could be more likely to go through WLST, which might be attributed to medical reasons, avoidance of suffering, and effective communication with family. ${ }^{30,31}$ Some parents may even change their attitude towards end-of-life care from full support to DNR and palliative care after building up trust and having focused communications with health care providers. ${ }^{32}$ Thus, early engagement of palliative care services, when available, and initiation of end-of-life discussions could smooth family acceptance of limiting life-sustaining interventions when deemed futile. ${ }^{26}$

Most deaths (69.3\%) occurred during the after hours in the current study, which is justified as the after hours constitute two thirds of the day. Although an increase in the number of F-CPR deaths during after hours (including weekends) was reported, there is limited information about other modes of death in correlation to working hours in PICUs. ${ }^{33,34}$ The increase in the number of F-CPR deaths during after hours could be due to a shortage of available medical expertise in homes compared to the working hours. ${ }^{35,36}$ However, the percentages of F-CPR deaths during working hours and after hours were similar to each other in our study. Furthermore, in relation to patient outcomes and timing of admissions or events, a previous prospective cohort study in a Saudi PICU found no significant difference in mortality amongst patients who were admitted to the PICU during working hours compared with after-hours. ${ }^{37}$ However, a shortage of staff or increased workload may contribute to higher mortality due to medical team fatigue, especially during the weekends, as other large data reports have described. ${ }^{33,38}$

Brain death or death by neurological criteria occurred in $6.9 \%$ of our cohort, which is less than previous local reports of $9.7 \%$ and $15 \%$ of other studies' cohorts. ${ }^{8,25}$ There were no significant interval changes in the national protocol for brain death diagnosis. ${ }^{10}$ Furthermore, there is a noticeable trend of decreasing rates of brain death diagnosis in the last 2 decades when standardized to cases per 1000 admissions per year: 7.7 in 2003 by Chehab et al, ${ }^{25} 6.3$ in 2014 by Alayed et al, ${ }^{8}$ and 3.2 in 2021 by our study. These differences raise the possibility of a potential decrease in local rates of pediatric brain death diagnoses that needs to be confirmed in a large multicenter epidemiological study. This trend could also be due to differences in patients' diagnoses.

However, the possibility of under-diagnosis is remote given to the tertiary level of the publishing centers. In contrast to relatively low rates of brain death diagnoses in Saudi Arabia, brain death occurred in $20.7 \%$ of pediatric deaths in a large database analysis in the US, with trends towards more brain death diagnosis per year and size of PICU. Meanwhile, data from New Zealand and Australia revealed an incremental increase in the rate of brain death diagnoses by $0.72 \%$ per year. ${ }^{5,39}$ The variability in brain death protocols are well-documented worldwide, which triggered the World Brain Death Project to provide consensus-based recommendations for brain death determination criteria. ${ }^{40}$ It is important to determine such critical diagnoses because brain death is the gateway for organ donation programs.

Study limitations. Our study was a retrospective data analysis, which was justified by the nature of mortality events as the outcome of interest and its rare occurrence. Also, a limitation that needs to be considered in interpreting this study's results is that the data came from a single hospital. The lack of autopsy-based confirmation of the cause of death was one limitation that we could not avoid due to the legal limitations of practicing autopsy according to the local law and regulations.

This study adds to previous reports addressing similar questions related to modes of death, updates the local PICU mortality data, and highlights for the first time infections attributed to pediatric mortality locally in view of various changes in current critical care settings and the changing landscape of national health care. This study partially illustrates the need for a large-scale epidemiological study of severe infections and emphasis on the adoption of quality projects to improve the management and outcome of sepsis. ${ }^{41}$ Furthermore, our study highlights the need for national initiatives to raise awareness of palliative care among the community and to provide specialized palliative care training programs to pediatric health care providers.

In conclusion, infections remain a significant cause of death in the PICU. Septic shock and lower respiratory tract infections were common causes of death in this cohort. Further improvement of prevention programs and early aggressive therapy for severe infections could lead to a significant improvement in pediatric mortality. While WLST mode of death was second to F-CPR mode, this report highlights the need for enhancing end-of-life decision making and palliative care programs. The decreasing rate of brain death diagnoses warrants further investigation. 
Acknowledgment. The authors gratefully acknowledge the Deanship of Scientific Research and Researchers Support \& Services Unit at King Saud University for their technical support. We also would like to thank Scribendi for English language editing and http://hodhodata.com/ for their statistical data analysis.

\section{References}

1. Burns JP, Sellers DE, Meyer EC, Lewis-Newby M, Truog RD. Epidemiology of death in the PICU at five U.S. teaching hospitals*. Crit Care Med 2014; 42: 2101-2108.

2. Siddiqui NU, Ashraf Z, Jurair H, Haque A. Mortality patterns among critically ill children in a pediatric intensive care unit of a developing country. Indian J Crit Care Med 2015; 19: 147-150.

3. Jung M, Park H, Kang D, Park J, Jeon K, Chung CR, et al. Age-specific distribution of diagnosis and outcomes of children admitted to ICUs: a population-based cohort study. Pediatr Crit Care Med 2019; 20: e301-e310.

4. Meert KL, Keele L, Morrison W, Berg RA, Dalton H, Newth CJ, et al. End-of-life practices among tertiary care PICUs in the United States: a multicenter study. Pediatr Crit Care Med 2015; 16: e231-e238.

5. Moynihan KM, Alexander PMA, Schlapbach LJ, Millar J, Jacobe S, Ravindranathan H, et al. Epidemiology of childhood death in Australian and New Zealand intensive care units. Intensive Care Med 2019; 45: 1262-1271.

6. Agra-Tuñas C, Rodriguez-Ruiz E, Rodríguez Merino E. How do children die in PICUs nowadays? A multicenter study from Spain. Pediatr Crit Care Med 2020; 21: e610-e616.

7. Trowbridge A, Walter JK, McConathey E, Morrison W, Feudtner C. Modes of death within a children's hospital. Pediatrics 2018; 142: e20174182.

8. Al-Ayed T, Rahmo N. Do not resuscitate orders in a Saudi pediatric intensive care unit. Saudi Med J 2014; 35: 561-565.

9. Bin Abdulrhman K, Al-Jabbary A, Alturik A, Al Barrak M, AlFifi M, Abuzaid S, et al. National policy and procedure for do-not-resuscitate (DNR) status [Internet]. Saudi Health Council; 2017 [accessed 2020 August 8]. Available from: http:// omranhospital.net/wp-content/uploads/2020/07/DNR-E.pdf

10. Saudi Center for Organ Transplantation. Annual report for organ trnsplantation in kingdom of Saudi Arabia [Internet]. SCOT; 2019 [accessed 2020 August 8]. Available from: https:// scot.gov.sa/en/Home/PDFViewer?pageid=13

11. Goldstein B, Giroir B, Randolph A. International pediatric sepsis consensus conference: definitions for sepsis and organ dysfunction in pediatrics. Pediatr Crit Care Med 2005; 6: 2-8.

12. Ayar G, Uysal Yazici M, Sahin S, Gunduz RC, Yakut HI, Oden Akman A, et al. Six year mortality profile of a pediatric intensive care unit: associaton between out-of-hours and mortality. Arch Argent Pediatr 2019; 117: 120-125.

13. McAllister DA, Liu L, Shi T, Chu Y, Reed C, Burrows J, et al. Global, regional, and national estimates of pneumonia morbidity and mortality in children younger than 5 years between 2000 and 2015: a systematic analysis. Lancet Glob Health 2019; 7: e47-e57.

14. United States Census Bureau. US and world population clock [Internet]. 2019 [accessed 2020 Dec 26]. Available from: https://www.census.gov/popclock/
15. General Authority for Statistics KSA. Population by sex, age groups and nationality mid 2018 [Internet]. 2019 [cited 26 Dec 2020]. Available from: https://www.stats.gov.sa/en/432018

16. Global Burden of Disease Child and Adolescent Health Collaboration, Kassebaum N, Kyu HH, Zoeckler L, Olsen HE, Thomas K, et al. Child and adolescent health from 1990 to 2015: findings from the global burden of diseases, injuries, and risk factors 2015 study. JAMA Pediatr 2017; 171: 573-592.

17. Li JJ, Chen YF, Lin YX. [Investigation of disease spectrum in the PICU of Shengjing hospital of China Medical University between 2005 and 2012]. Zhongguo Dang Dai Er Ke Za Zhi 2013; 15: 472-476. [in Chinese].

18. Punchak M, Hall K, Seni A, Buck WC, DeUgarte DA, Hartford E, et al. Epidemiology of disease and mortality from a PICU in Mozambique. Pediatr Crit Care Med 2018; 19: e603-e610.

19. Stewart CE, Radia T, Ghafoor K. Paediatric sepsis, the underrecognised killer: quality improvement initiative of outreach teaching in paediatric sepsis. Arch Dis Child Educ Pract Ed 2017; 102: 278-280.

20. Randolph AG, McCulloh RJ. Pediatric sepsis: important considerations for diagnosing and managing severe infections in infants, children, and adolescents. Virulence 2014; 5: 179-189.

21. Kissoon N, Uyeki TM. Sepsis and the global burden of disease in children. JAMA Pediatr 2016; 170: 107-108.

22. Jiang W, Wu M, Zhou J, Wang Y, Hao C, Ji W, et al. Etiologic spectrum and occurrence of coinfections in children hospitalized with community-acquired pneumonia. BMC Infect Dis 2017; 17: 787.

23. Sankar J, Garg M, Ghimire JJ, Sankar MJ, Lodha R, Kabra SK. Delayed administration of antibiotics beyond the first hour of recognition is associated with increased mortality rates in children with sepsis/severe sepsis and septic shock. J Pediatr 2021; 233: 183-190.

24. Schmatz M, Srinivasan L, Grundmeier RW, Elci OU, Weiss SL, Masino AJ, et al. Surviving sepsis in a referral neonatal intensive care unit: association between time to antibiotic administration and in-hospital outcomes. J Pediatr 2020; 217: 59-65.

25. Chehab M. Modes of death in a paediatric intensive care unit in the Muslim community of Saudi Arabia. Clinical Intensive Care 2003; 14: 135-139.

26. Audigé M, Gillam L, Stark Z. Treatment limitation and advance planning: hospital-wide audit of paediatric death. J Paediatr Child Health 2020; 56: 893-899.

27. Hileli I, Weyl Ben Arush M, Hakim F, Postovsky S. Association between religious and socio-economic background of parents of children with solid tumors and DNR orders. Pediatr Blood Cancer 2014; 61: 265-268.

28. Hafez SA, Snethen JA, Ngui E, Ellis J, Taani M. Pediatric end of life care: impact of Islamic faith. West J Nurs Res 2021: 1939459211016503.

29. Aljethaily A, Al-Mutairi T, Al-Harbi K, Al-Khonezan S, Aljethaily A, Al-Homaidhi HS. Pediatricians' perceptions toward do not resuscitate: a survey in Saudi Arabia and literature review. Adv Med Educ Pract 2020; 11: 1-8.

30. Ramelet AS, Bergstraesser E, Grandjean C, Dorsaz A, FahrniNater P, Cignacco E, et al. Comparison of end-of-life care practices between children with complex chronic conditions and neonates dying in an ICU versus non-ICUs: a substudy of the pediatric end-of-life care needs in Switzerland (PELICAN) project. Pediatr Crit Care Med 2020; 21: e236-e246. 
31. Johnston EE, Bogetz J, Saynina O, Chamberlain LJ, Bhatia $S$, Sanders L. Disparities in inpatient intensity of end-of-life care for complex chronic conditions. Pediatrics 2019; 143: e20182228.

32. Temsah MH. Ethical considerations about changing parental attitude towards end-of-life care in twins with lethal disease. Sudan J Paediatr 2018; 18: 76-82.

33. Bhanji F, Topjian AA, Nadkarni VM, Praestgaard AH, Hunt EA, Cheng A, et al. Survival rates following pediatric in-hospital cardiac arrests during nights and weekends. JAMA Pediatr 2017; 171: 39-45.

34. Bhonagiri D, Pilcher DV, Bailey MJ. Increased mortality associated with after-hours and weekend admission to the intensive care unit: a retrospective analysis. Med J Aust 2011; 194: 287-292.

35. Rehder KJ, Giuliano JS Jr, Napolitano N, Turner DA, Nuthall G, Nadkarni VM, et al. Increased occurrence of tracheal intubation-associated events during nights and weekends in the PICU. Crit Care Med 2015; 43: 2668-2674.

36. Stanley LJ. Association among neonatal mortality, weekend or nighttime admissions and staffing in a neonatal intensive care unit [Internet]. Digital Commons USF; 2008 [accessed 2021 June 1]. Available from: https://digitalcommons.usf.edu/ etd/511/
37. Thabet FC, alHaffaf FA, Bougmiza IM, Bafaqih HA, Chehab MS, alMohaimeed SA. Off-hours admissions and mortality in PICU without 24-hour onsite intensivist coverage. J Intensive Care Med 2020; 35: 694-699.

38. Appiah J, Salie S, Argent A, Morrow B. Characteristics, course and outcomes of children admitted to a paediatric intensive care unit after cardiac arrest. South African J Crit Care 2018; 34: 58-64.

39. Kirschen MP, Francoeur C, Murphy M, Traynor D, Zhang B, Mensinger JL, et al. Epidemiology of brain death in pediatric intensive care units in the United States. JAMA Pediatr 2019; 173: 469-476.

40. Greer DM, Shemie SD, Lewis A, Torrance S, Varelas P, Goldenberg FD, et al. Determination of brain death/death by neurologic criteria: the world brain death project. JAMA 2020; 324: 1078-1097.

41. Hasan GM, Al-Eyadhy AA, Temsah MA, Al-Haboob AA, Alkhateeb MA, Al-Sohime F. Feasibility and efficacy of sepsis management guidelines in a pediatric intensive care unit in Saudi Arabia: a quality improvement initiative. Int J Qual Health Care 2018; 30: 587-593. 
Deaths in the PICU ... Al-Eyadhy et al

Appendix 1 - Time of death in relation to demographic and clinical characteristics, bivariate analysis of mortalities time of death (working/after hours).

\begin{tabular}{|c|c|c|c|c|}
\hline \multirow[t]{2}{*}{ Demographics } & \multicolumn{2}{|c|}{ Time of death } & \multirow[t]{3}{*}{ Test statistic } & \multirow[t]{3}{*}{$P$-value } \\
\hline & Working hours $(\mathrm{n}=31)$ & After hours $(\mathrm{n}=70)$ & & \\
\hline & \multicolumn{2}{|c|}{ n (\%) } & & \\
\hline \multicolumn{5}{|l|}{ Gender } \\
\hline $\begin{array}{l}\text { Female } \\
\text { Male }\end{array}$ & $\begin{array}{l}20(64.5) \\
11(35.5)\end{array}$ & $\begin{array}{l}32(45.7) \\
38(54.3)\end{array}$ & $\chi^{2}(1)=3.04$ & 0.081 \\
\hline Age (months), mean $\pm S D$ & $52 \pm 57.3$ & $48.91 \pm 51.9$ & $t(99)=0.30$ & 0.786 \\
\hline Hospital admission time & $26(83.9)$ & $60(85.7)$ & $\chi^{2}(1)=0.1$ & 0.810 \\
\hline \multicolumn{5}{|l|}{ Length of stay } \\
\hline $\begin{array}{l}\text { Hospital, median (Qrt.1, Qrt.3) } \\
\text { PICU, median (Qrt.1, Qrt.3) }\end{array}$ & $\begin{array}{c}10(5,30) \\
7(4,18)\end{array}$ & $\begin{array}{l}9.5(2,37) \\
7.5(2,20)\end{array}$ & $\begin{array}{l}U(101)=1034 \\
U(101)=1071\end{array}$ & $\begin{array}{l}0.707 \\
0.921\end{array}$ \\
\hline \multicolumn{5}{|l|}{ Mode of death } \\
\hline $\begin{array}{l}\text { F-CPR } \\
\text { WLST } \\
\text { Brain death }\end{array}$ & $\begin{array}{c}15(48.4) \\
14(45.2) \\
2(6.5)\end{array}$ & $\begin{array}{c}36(51.4) \\
29(41.4) \\
5(7.1)\end{array}$ & $\begin{array}{c}\chi^{2}(1)=4.1 \\
\chi^{2}(1)=0.122 \\
\chi^{2}(1)=0.020\end{array}$ & $\begin{array}{l}0.778 \\
0.726 \\
0.900\end{array}$ \\
\hline Presented with infections upon admission & $19(61.3)$ & $44(62.9)$ & $\chi^{2}(1)=0.022$ & 0.881 \\
\hline DNR order & $15(48.4)$ & $35(50)$ & $\chi^{2}(1)=0.022$ & 0.881 \\
\hline \multicolumn{5}{|l|}{ Cause of death } \\
\hline $\begin{array}{l}\text { Shock - septic } \\
\text { Lower respiratory infection } \\
\text { Cardiac diseases } \\
\text { Respiratory failure secondary to CNS disease } \\
\text { Tumors } \\
\text { Pulmonary hemorrhage } \\
\text { Others* }\end{array}$ & $\begin{array}{l}15(48.4) \\
3(9.7) \\
5(16.1) \\
2(6.4) \\
1(3.2) \\
2(6.4) \\
3(9.7)\end{array}$ & $\begin{array}{c}16(22.8) \\
16(22.8) \\
7(10.0) \\
10(14.3) \\
6(8.6) \\
4(5.7) \\
11(15.7)\end{array}$ & $\chi^{2}(6)=11.375$ & 0.078 \\
\hline
\end{tabular}

